\title{
The GABA-Withdrawal Syndrome: A Model of Local Status Epilepticus
}

\author{
Carmen Silva-Barrat ${ }^{1 \dagger}$, Jean Champagnat ${ }^{2}$ and Christian Menini ${ }^{1}$ \\ 'Laboratoire de Génétique de la Neurotransmission et des Processus Neurodégénératifs. UMR 9923, \\ CNRS. 75634 Paris, France; ${ }^{2}$ Institut Alfred Fessard. CNRS. 91198 Gif sur Yvette, France
}

\section{SUMMARY}

The GABA-withdrawal syndrome (GWS) is a model of local status epilepticus following the interruption of a chronic GABA infusion into the rat somatomotor cortex. GWS is characterized by focal epileptic electroencephalographic discharges and associated contralateral myoclonus. In neocortical slices obtained from GWS rats, most neurons recorded in the GABA-infused area are pyramidal neurons presenting bursting properties. The bursts are induced by white-matter stimulation and/or intracellular depolarizing current injection and correlate with a decrease of cellular sensitivity to GABA, caused by its prolonged infusion. This effect is related to a calcium influx that may reduce the $\mathrm{GABA}_{A}$ receptormediated inward current and is responsible for the bursting properties. Here we present evidence for the involvement of calcium- and NMDA-induced currents in burst genesis. We also report modulatory effects of noradrenaline appearing as changes on firing patterns of bursting and nonbursting cells. Complementary histochemical data reveal the existence of a local noradrenergic hyperinnervation and an ectopic expression of tyrosine hydroxylase mRNAs in the epileptic zone.

\footnotetext{
${ }^{\mp}$ Corresponding author:

Laboratoire d'Epilepsie Expérimentale, UMR 9923, CNRS, Faculté Pitié-Salpétrière, 91 bd. de l'Hôpital, 75634 Paris Cedex 13, France.

tél: (33) 01-40-77-98-27, fax: (33) 01-40-77-97-89

e-mail : silvabar@ccr.jussieu.fr
}

\section{INTRODUCTION}

For several years, our group in Gif-sur-Yvette (France) worked on a model of reflex epilepsy, the photosensitive epilepsy of Papio papio baboons (Killam et al. 1967). When these predisposed baboons are submitted to intermittent light stimulation, generalized paroxysmal manifestations appear in the frontal motor cortex (Morrell et al., 1969). We had clearly demonstrated that generalized paroxysmal manifestations originate in the motor cortex (Silva-Barrat et al. 1988), when Simon Brailowsky came to our laboratory. Simon proposed to block the epileptic manifestations of baboons by means of a chronic infusion of $\gamma$-aminobutyric acid (GABA) into the motor cortex of these animals. We performed 4- to 7-day infusions by means of osmotic minipumps and observed the disappearance of epileptic manifestations. After cessation of the GABA infusion, however, a rebound of brain excitability was observed, as evidenced by the presence of epileptogenic discharges localized in the infused area (Brailowsky et al., 1987; 1989). The phenomenon appearing after the interruption of the chronic GABA infusion was named the "GABAwithdrawal syndrome" (GWS). Initially, we demonstrated that GWS is not the consequence of the genetic epileptic predispositon of baboons, and we tested the effects of chronic intracortical GABA infusions in non-photosensitive animals. Indeed, we reproduced GWS not only in nonepileptic baboons but also in normal rats. After returning to Mexico, Simon and his group reproduced GWS in hippocampal slices of rats (Garciaugalde et al., 1992). Finally, this phenomenon 
could be considered a new model of focal epilepsy (Brailowsky et al., 1988). Thanks to this discovery, a new series of epileptic studies has been initiated that we want to present briefly as our tribute to Simon.

\section{GWS AS A MODEL OF LOCAL STATUS EPILEPTICUS IN THE RAT: IN VIVO AND IN VITRO STUDIES.}

Both EEG and clinical studies (Brailowsky et al., 1988) have established that GWS is a status epilepticus resembling the epilepsia partialis continua, a partial status epilepticus that was described in human patients by Kojewnikow (1895). GABA is infused into the motor cortex of rats for 5 days. Upon cessation of the infusion, an epileptogenic focus appears, characterized by continuous EEG discharges at high frequency, localized in the infused area and associated with myoclonic twitches of the contralateral corresponding body territory. The epileptic manifestations appear $20 \mathrm{~min}$ after the infusion interruption, persist for $48 \mathrm{~h}$ on average, and never generalize into tonicclonic seizures. GWS is an interesting model resulting from a local manipulation that is associated with a focal epilepsy. GWS is different from other epilepsy models that are provoked by topical application of toxic or irritant drugs or even convulsant drugs (such as penicillin, kainate or pilocarpine) provoking diffuse abnormalities.

Using conventional intracellular recording and stimulation techniques, we studied neuronal activity in the epileptogenic focus in neocortical slices obtained from rats presenting GWS (SilvaBarrat et al., 1989). The presence of a great number of burst-generating neurons in an area close to the GABA-infused site has enabled the analysis of epileptic-like pattern generation by comparing bursting and nonbursting cells. Bursting neurons present paroxysmal depolarizing shifts (PDSs) and bursts of action potentials (APs) after synaptic activation by white matter stimulation (WM) and/or intrinsic bursts of APs after intracellular injection with a depolarizing current. Nonbursting neurons present neither synaptic nor intrinsic bursting properties. In this paper, we will first describe the cellular types recorded in the GWS epileptic focus, and we will show that the bursting cells are desensitized to GABA. We will also present some ionic mechanisms that are involved in the genesis of the epileptic activity, and finally discuss some neuromodulatory mechanisms involved in this activity.

\section{PHYSIOLOGICAL AND MORPHOLOGICAL IDENTIFICATION OF NEURONS SHOWING BURSTING ACTIVITY}

Histological observation of slices showed that the recorded cells are impaled at the periphery of the necrotic zone $(0.7$ to $1.2 \mathrm{~mm})$ because of cannula penetration and GABA infusion. The soma of biocytine-labeled neurons are localized in layer V (Fig. 1A). Cells presenting synaptic and/or intrinsic bursts have a pyramidal-shaped soma with a basal dendritic arborization, an apical dendrite, and an axon from the basal region of the soma (Fig. 1B) (Silva-Barrat et al., 1994). Synaptic bursts are evoked by suprathreshold white matter stimulation. The bursts consist of 38 APs riding on the large depolarizing wave or PDS, EPSPs are obtained by decreasing the stimulus intensity to values subthreshold for AP elicitation (Fig. 1C). Intrinsic bursts induced by depolarizing current injection consist of 2-5 APs riding on a slow wave (Fig. 1D). In nonbursting cells, the white-matter stimulation subthreshold for AP elicitation evokes a synaptic potential that at the resting membrane potential is mainly depolarizing. These cell groups are not different in their resting membrane potential, input resistance, and AP amplitude (Silva-Barrat et al., $1989 ; 1992 ; 1994)$. Our first results therefore showed a large population of cells, most of them pyramidal cells, presenting bursting properties, with respect to those seen in other models of epilepsy that were provoked by topical or by 
systemic administration of compounds inhibiting GABA transmission (Connors et al., 1982). Our data suggest that cortical slices retain in vitro the epileptic characteristics presented in vivo during the GWS.
A

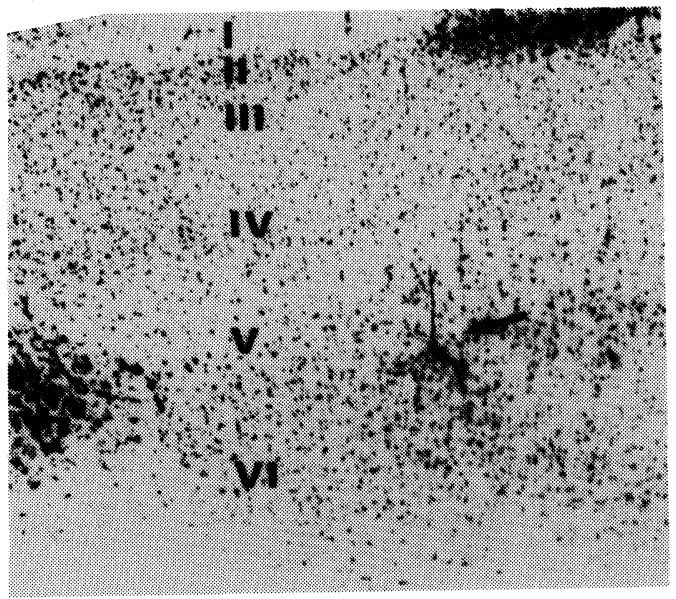

\section{B}

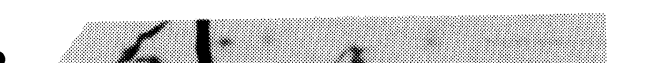




\section{BURSTING NEURONS ARE DESENSITIZED TO GABA.}

Could an abnormal GABAergic transmission explain the epileptic manifestations of the GWS? To answer this question, we studied the effects of GABA application on bursting cells and compared these effects with those obtained after the same application on nonbursting cells. We observed that
GABA at $1.6 \mu \mathrm{M}$ was able to block APs evoked by synaptic stimulation in nonbursting cells recorded in slices from saline infused rats (Fig. 2A), whereas the same dose was inefficient on PDSs recorded in slices from GWS rats (Fig. 2B). Similar results were observed during applications of isoguvacine, a specific $\mathrm{GABA}_{\mathrm{A}}$ agonist, thus indicating that bursting cells in GWS are indeed tolerant to GABA (Silva-Barrat et al., 1989).

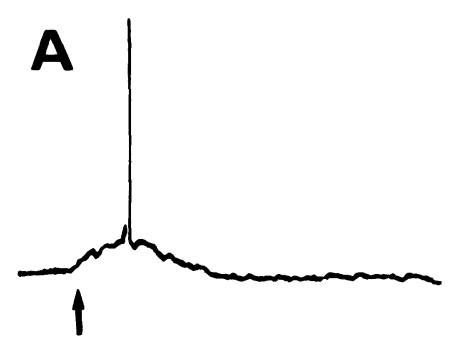

\section{6}
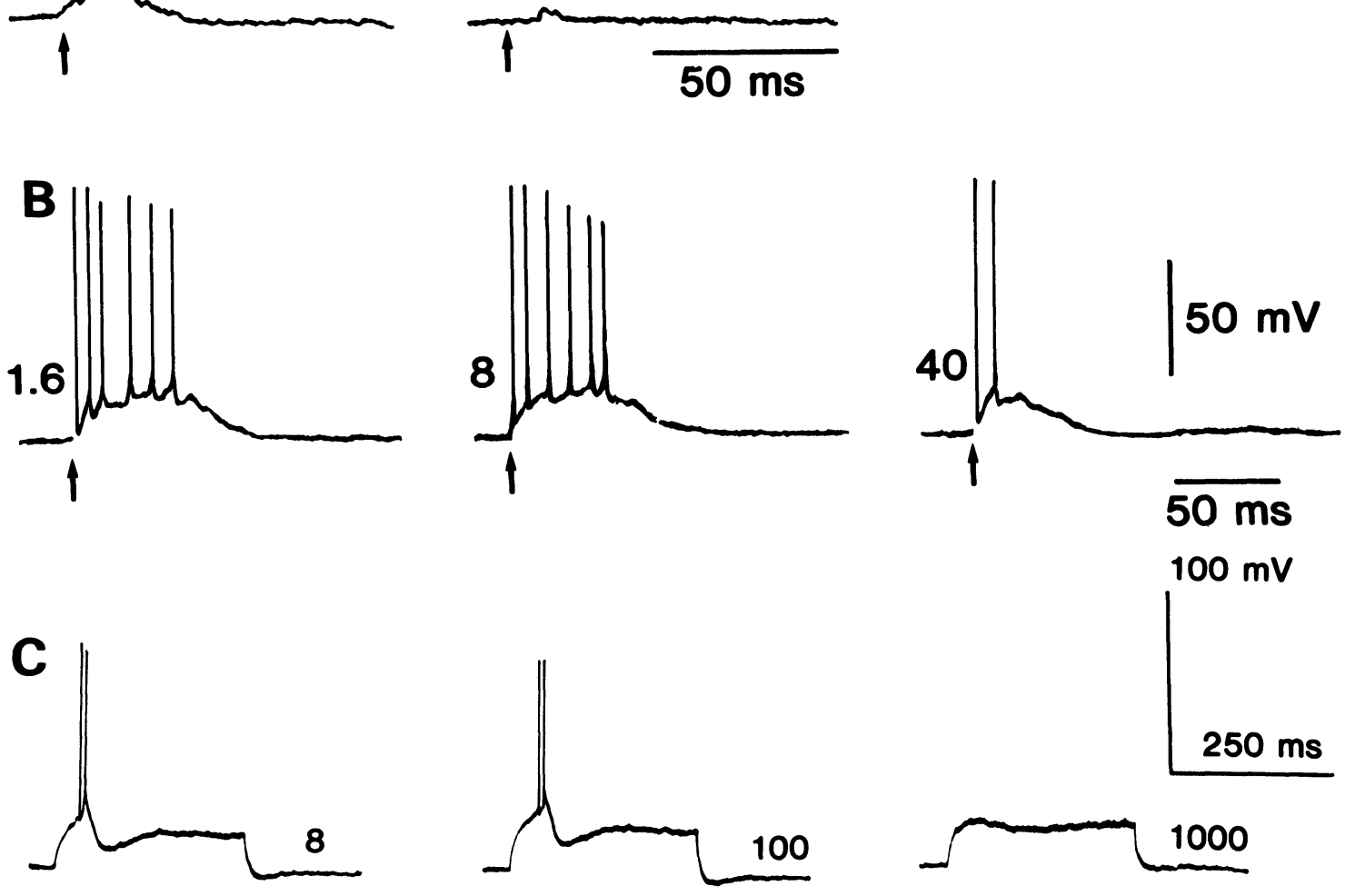

Fig. 2: GABA effects on synaptic potentials evoked by white matter stimulation (arrow). A: EPSPs induced in a saline-infused slice, before and during $1.6 \mu \mathrm{M}$ of GABA $(5 \mathrm{~min})$. B: paroxysmal depolarization shift induced in a slice obtained from a GABA-withdrawal syndrome rat during $1.6,8$, and $40 \mu \mathrm{M}$ of GABA application ( $5 \mathrm{~min})$. Note the different time scales. C: Effects of GABA ( $5 \mathrm{~min}$ ) on intrinsic bursts induced by intracellular depolarizing current $(8,100$, and $1000 \mu \mathrm{M})$. Note that intrinsic bursts are more resistant to GABA than to PDSs. 


\section{$\mathrm{CA}^{2+}$ IONIC MECHANISMS INVOLVED IN BURSTING ACTIVITY}

The decrease in GABA efficacy could be related to a $\mathrm{Ca}^{2+}$ influx that may reduce the $\mathrm{GABA}_{\mathrm{A}}$ receptor-mediated inward current and seems to be responsible for the bursting properties. The role of $\mathrm{Ca}^{2+}$ currents and of $\mathrm{Ca}^{2}$-dependent processes in determining bursting patterns was studied by using organic and inorganic antagonists of $\mathrm{Ca}^{2}$ channels. The organic $\mathrm{Ca}^{2}$ antagonist verapamil, as well as the inorganic blockers of $\mathrm{Ca}^{2}$ channels $\mathrm{Co}^{2+}, \mathrm{Mg}^{2+}$, and $\mathrm{Cd}^{2+}$, reduce the amplitude of PDSs, block the associated bursts, and also block intrinsic bursts. None of the $\mathrm{Ca}^{2+}$ antagonists affect EPSPs induced in bursting or nonbursting cells by synaptic stimulation at low intensity or the EPSP-single AP sequences evoked in nonbursting cells by stronger stimuli (SilvaBarrat et al., 1992). Therefore the effects of $\mathrm{Ca}^{2+}$ blockers are not related to suppression of $\mathrm{Ca}^{2+}$ dependent release of transmitters.

In addition, intracellular application of ethylene glycol-bis-( $\beta$-aminoethyl ether)-N,N,N',N'-tetraacetic acid (EGTA), a $\mathrm{Ca}^{2+}$ chelator, increased the amplitude and duration of PDSs and favored the appearance of additional APs during intrinsic and synaptically-induced bursts (Silva-Barrat et al., 1992). The involvement of L channels, slowly inactivating, in bursting activity as suggested in other preparations (Johnston et al., 1980) would explain the high sensitivity to $\mathrm{Ca}^{2+}$ blockers and the regulatory effects of intracellular $\mathrm{Ca}^{2+}$ ions sensitive to the injection of EGTA.

Bursting activities are also affected in conditions of reduced outward $\mathrm{K}^{+}$currents. Thus tetraethylammonium (TEA), at doses that do not change input resistance, spike duration, or first interspike time interval, abolish the burst-terminating process and induce plateau-like potentials (up to $500 \mathrm{~ms}$ ) that are tetrodoxin-resistant and blocked by the $\mathrm{Ca}^{2+}$ antagonists $\mathrm{Cd}^{2+}$ and $\mathrm{Co}^{2+}$ (Silva-Barrat \& Champagnat, 1995). Therefore, it appears that bursts during GWS are generated by $\mathrm{Ca}^{2+}$-dependent plateau potentials that are terminated by $\mathrm{a} \mathrm{K}^{+}$ current that is highly sensitive to TEA.

Given that the entry of $\mathrm{Ca}^{2+}$ depends not only on voltage-dependent $\mathrm{Ca}^{2+}$ channels but also on receptor-operated $\mathrm{Ca}^{2+}$ channels, we tested the effects of selective antagonists of NMDA receptors on bursting activities. Bath applications of APH (DL-2amino-7-phosphonoheptanoate) and APV (DL-2amino-5-phosphonovalerate), at doses of 10 to $50 \mu \mathrm{M}$, reversibly reduced the amplitude and duration of PDSs (Fig. 3).
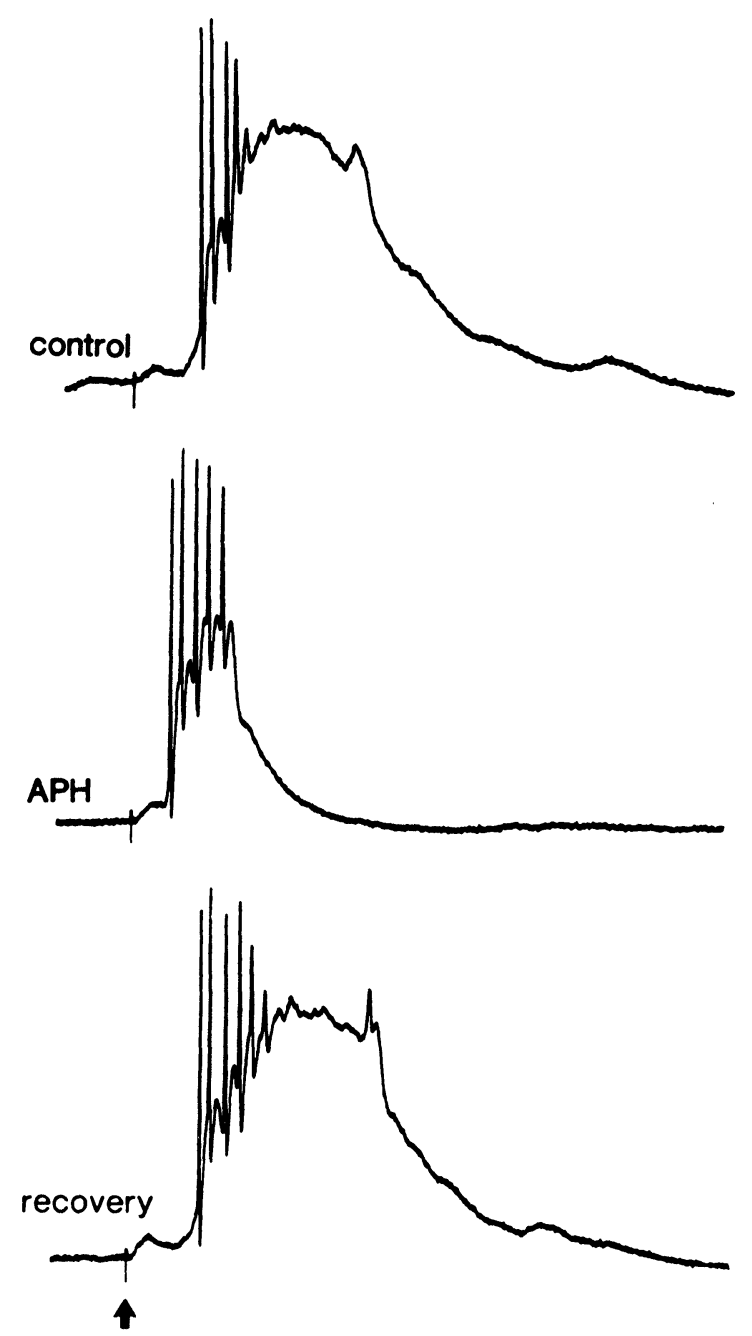

Fig. 3: Effects of DL-2-amino-7-phosphono-heptanoic acid (APH) on paroxysmal depolarization shifts. Paroxysmal depolarization shift, induced by white matter stimulation before (control), during (APH), and after (recovery) APH application $(20 \mu \mathrm{M}) . \mathrm{E}_{\mathrm{m}}=-74 \mathrm{mV}$. 
At the same dosage, NMDA antagonists do not affect the EPSPs induced by a stimulation at low intensity in bursting or nonbursting neurons nor the firing pattern induced by intracellular depolarizing current injection in the same cells. This observation suggests that NMDA receptors play a specific role in the induction of PDSs
(Silva-Barrat et al., 1992) as similarly shown for epileptiform bursting in the pyramidal hippocampal neurons (Dingledine et al., 1986). In summary, PDSs result from the cooperation of at least three different currents: (1) the classical EPSP that is insensitive to NMDA antagonists, (2) a later component (the depolarizing wave) that depends
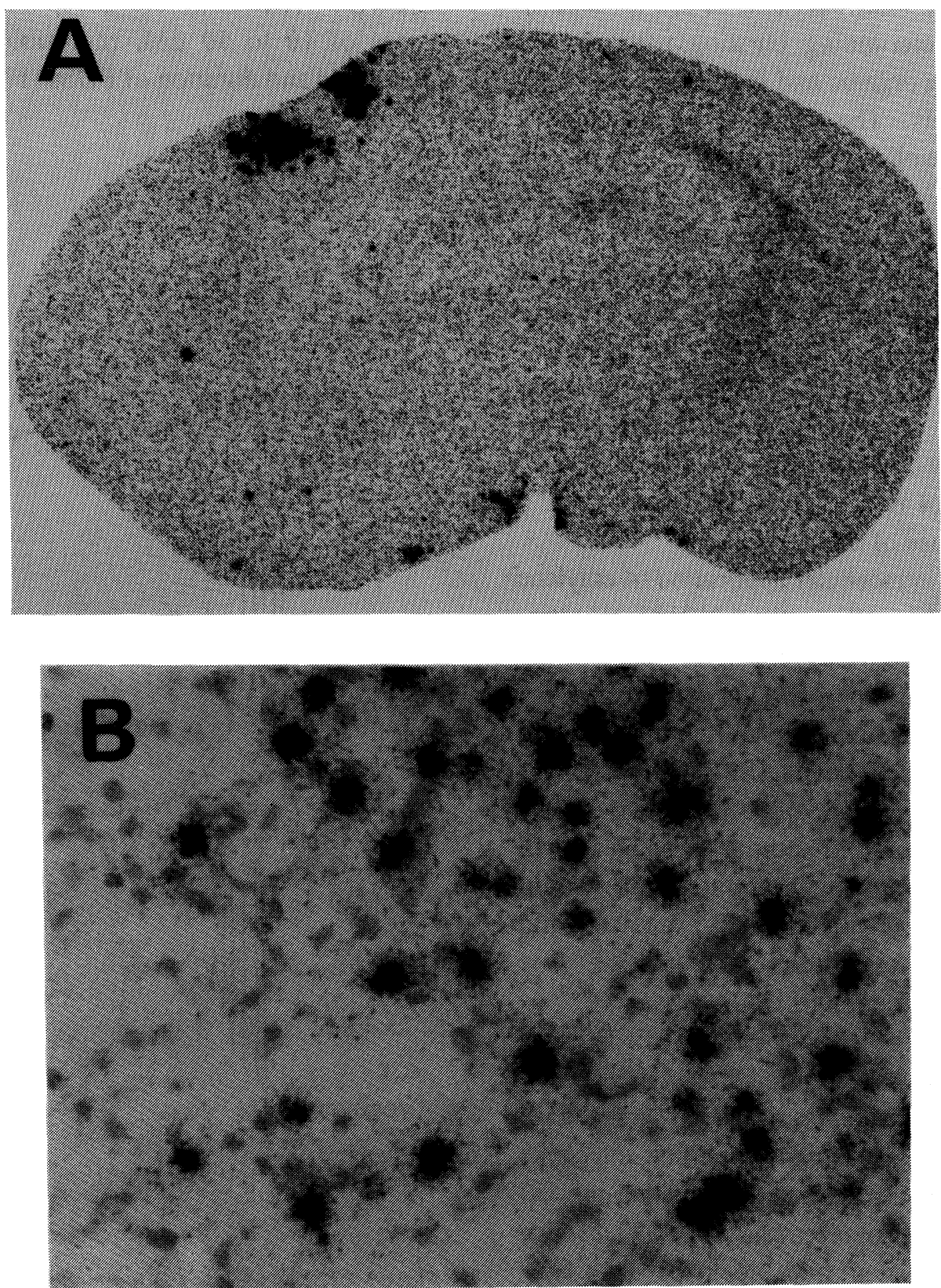

Fig. 4: Overexpression of tyrosine hydroxylase mRNAs revealed by in situ hybridization in the epileptic focus zone of a rat presenting GABA-withdrawal syndrome. A: densitometric figure of a brain slice labeled with a radioactive tyrosine hydroxylase-specific oligonucleotide. B: Magnified photomicrograph $(\times 250)$ of the labeled zone, showing neurones with high density of silver grains. 
on NMDA receptor activation, and (3) the $\mathrm{Ca}^{2+}$ voltage-dependent current that is responsible for bursts of APs and sensitive to $\mathrm{Ca}^{2+}$ antagonists, as shown above.

\section{NEUROMODULATORY ROLE OF NORADRENALINE IN GWS}

Given the preceding results, we wanted to verify if neurotransmitters other than GABA and glutamate are involved in GWS. An immunocytochemical study revealed an important labeling of noradrenergic cell bodies and terminals in a zone corresponding to the epileptic focus (Araneda et al., 1994). This zone also presents an ectopic expression of tyrosine hydroxylase mRNAs, which has been revealed by in situ hybridization and which could lead to noradrenergic neosynthesis in modified cells (Menini et al., 1992) (Fig. 4), given that tyrosine hydroxylase mRNAs are not normally expressed in the cerebral cortex of adult rats.
The data presented here lead to the following question: what are the functional consequences of the noradrenaline expressed in GWS at the level of the epileptic focus? Bath norepinephrine (NE) applications provoked a small cell membrane depolarization associated with a decrease in input $\mathrm{K}^{+}$conductance that is not significantly different for bursting and nonbursting cells (Silva-Barrat et al., 1994). In addition, the NE-induced depolarization replaces the intrinsic bursts by a regular firing of single APs and causes intrinsic bursts to appear during previously subthreshold depolarizing current pulses. These NE-increased activities are abolished by $\mathrm{Ca}^{2+}$ channels antagonists.

In nonbursting cells recorded from slices of GWS but not from saline-infused rats, NE promotes the appearance of bursts after WM stimulation, as well as during depolarizing current injection. Thus, a threshold current pulse inducing a single AP before NE application became efficient after NE application in inducing bursts of APs (Fig. 5). The possibility that these bursts result indirectly from
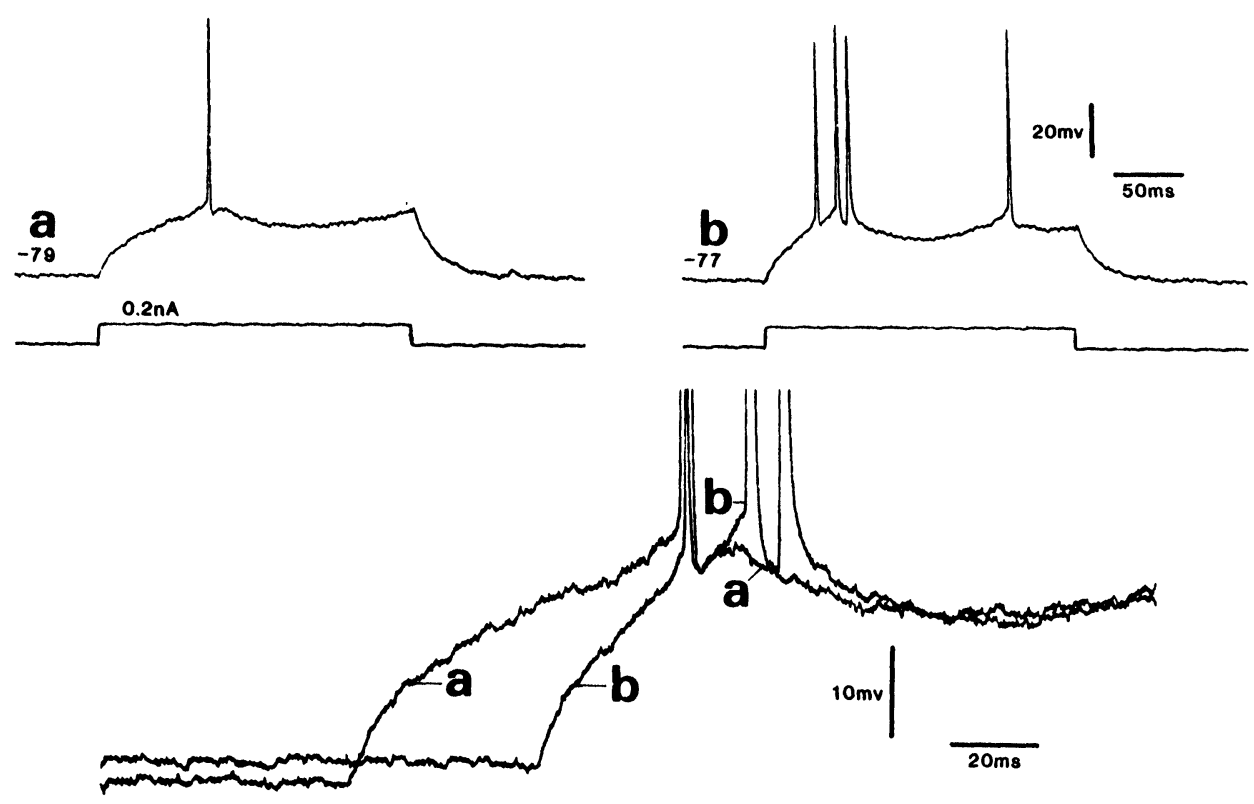

Fig. 5: Norepinephrine $(10 \mu \mathrm{M})$ promotes burst appearance in nonbursting cells. Response to suprathreshold (0.2nA) intracellular depolarizing current pulse for eliciting a single AP in control (a) and during norepinephrine-induced depolarization (b). Bottom: superimposition of enlarged records a and $b$, taking the fast hyperpolarization peak as a reference. 
the NE-induced depolarization and from the increase in input resistance has been eliminated by compensating the NE-induced depolarization. The NE-induced bursts are generated by $\mathrm{Ca}^{2+}$. dependent currents because they are transformed into a regular firing of APs by $\mathrm{Ca}^{2+}$-channel blockers. Generation of bursts in nonbursting cells has been found to be related to an increased afterdepolarization following the AP (Fig. 5). It is therefore possible that the afterdepolarization activates $\mathrm{Ca}^{2+}$ currents, which in turn, could generate extra spikes grouped in a burst. NE has not been previously reported to induce bursting patterns in cortical neurons, so we can suggest
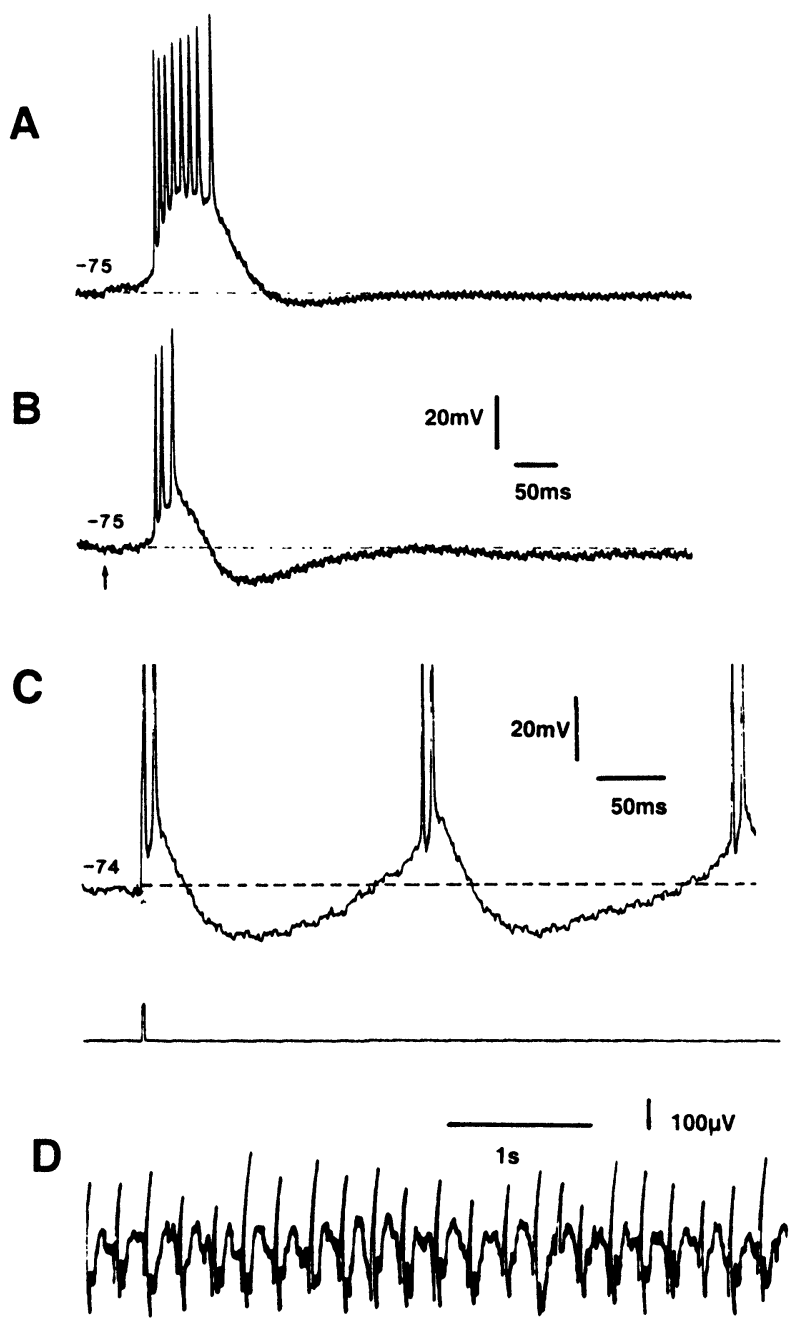

Fig. 6: Effects of norepinephrine on paroxysmal depolarization shifts recorded in a bursting cell. A and B: paroxysmal depolarization shifts recorded in a bursting cell before and after norepinephrine application, respectively, at the same resting membrane potential. Norepinephrine provoked a decrease in paroxysmal depolarization shift amplitude and duration, a decrease in the number of Aps, and an increase in the afterhyperpolarization amplitude. C: Effects of norepinephrine on burst frequency: Note that the shortening of paroxysmal depolarization shifts and the increase in afterhyperpolarizations facilitates the appearance of extraburst during norepinephrine application and determines their frequency. D: Electroencephalographic spikes observed in living animals; Note that their frequency corresponds to the frequency of paroxysmal depolarization shifts, namely, $5 \mathrm{~Hz}$ during the peak of the norepinephrine-induced depolarization. 
that NE unmasks potential bursting capabilities by increasing $\mathrm{Ca}^{2+}$ currents in nonbursting cells of GWS rats.

An other specific effect of NE observed in bursting cells of GWS rats concerns the afterhyperpolarization (AHP) that follows PDS triggered by WM stimulation (Fig. 6A). We observed that AHP increases during NE application, resulting in a $50 \%$ decrease in amplitude and duration of PDSs (Fig. 6B) and an increase of their frequency up to $5 \mathrm{~Hz}$ (Fig. 6C). Such bursts are generated by interactions between $\mathrm{Ca}^{2+}$ currents responsible for burst generation, $\mathrm{K}^{+}$currents involved in AHP generation, and the strength of the $\mathrm{K}+$ conductance decrease associated with the NE-induced depolarization. The AHPs after PDSs could be responsible for the intervals between EEG spikes observed in living animals (Fig. 6D).

The data presented above show that NE has differential effects on neurons recorded in the epileptic focus area of GWS rats in comparison with those recorded in the normal cortex: NE promotes appearance of bursts in nonbursting cells and accelerates the postburst repolarization in bursting cells. Both effects are probably related to an increase of GWS-related $\mathrm{Ca}^{2+}$ currents. This hypothesis is supported by anatomical data revealing the existence of a local noradrenergic hyperinervation in the epileptic focus zone.

\section{CONCLUSIONS}

The interruption of a chronic intracortical GABA infusion into the somatomotor cortex of rats provokes the appearance of a GABAwithdrawal syndrome that is associated with an epileptic focus localized to the infused site. At the periphery of this infusion site, numerous neurons present bursts of APs resulting from a tolerance to GABA, correlated to an exaggerated $\mathrm{Ca}^{2+}$ entry as a consequence of the prolonged GABA infusion. Such bursts, and by consequence the epileptic focus, are subject to a noradrenergic modulation resulting from an ectopic expression of this neurotransmitter at the level of the GABA infusion site. As immunocytochemical data (Araneda et al., 1994) and in situ hybridization studies (Menini et al., 1992) have revealed that in addition to noradrenaline, choline acetyltransferase is also overexpressed in the GWS focus area, we suggest that the GWS represents a valid model of transitory epilepsy for studying the physiological consequences of the reorganization of neuronal networks that is due to the expression of abnormal cellular phenotypes in this epileptic focus zone.

\section{ACKNOWLEDGEMENT}

This work was partly supported by a grant from ECOS, $n^{\circ}$ U95E01

\section{REFERENCES}

Araneda S, Silva-Barrat C, Menini C, Naquet R. High expression of noradrenaline, choline acetyltransferase and glial fibrillary acidic protein in the epileptic focus consecutive to GABA withdrawal. An immunocytochemical study. Brain Res 1994; 655: 135-146.

Brailowsky S, Menini C, Silva-Barrat C, Naquet R. Epileptogenic gamma-aminobutyric acid-withdrawal syndrome after chronic, intracortical infusion in baboons. Neurosci Lett 1987; 74: 75-80.

Brailowsky S, Kunimoto M, Menini C, Silva-Barrat C, Riche D, Naquet R. The GABA-withdrawal syndrome: a new model of focal epileptogenesis. Brain Res 1988; 442: 175-179.

Brailowsky S, Silva-Barrat C, Menini C, Riche D, Naquet R. Effects of localized, chronic GABA infusions into different cortical areas of the photosensitive baboon, Papio-papio. Electroenceph Clin Neurophysiol 1989; 72: 147-156.

Connors BW, Gutnick MJ, Prince DA. Electrophysiological properties of neocortical neurons in vitro. J Neurophysiol 1982; 48: 1302-1320.

Dingledine R, Hynes MA, King GL. Involvement of $\mathrm{N}$-methyl-D-Aspartate receptors in epileptiform bursting in the rat hippocampal slice. J Physiol (London) 1986; 380: 175-189.

Garciaugalde G, Galagarra E, Bargas J, Brailowsky S. Hyperexcitability of hippocampal CA1 region 
in brain slices after GABA withdrawal. Neurosci Lett 1992; 147: 229-232.

Johnston D, Hablitz JJ, Wilson WA. Voltage clamp discloses slow inward current in hippocampal burst-firing neurons. Nature (London) 1980; 286: 391-393.

Killam KF, Killam EK, Naquet R. An animal model of light sensitive epilepsy. Electroenceph clin Neurophysiol 1967; 22: 497-513.

Kojewnikow L. Eine besondere Form von corticaler Epilepsie Neurol Zbl1895; 14: 47-48.

Menini C, Abitbol M, Rhyner T, Wiklund L, Naquet R, Mallet J. Modulations spécifiques de l'expression génique au cours du syndrome d'abstinence au GABA. Premier Colloque de la Société des Neurosciences de Langue Française. Strasbourg, Mai 1992; 40.

Morrell F, Naquet R, Menini C. Microphysiology of cortical single neurons in Papio papio. Electroenceph clin Neurophysiol 1969; 27: 708-709.

Silva-Barrat C., Brailowsky S., Levesque G., Menini
Ch. Epileptic discharges induced by intermittent light stimulation in photosensitive baboons: A current source density study. Epilepsy Res 1988; 2: 1-8.

Silva-Barrat C, Champagnat J, Brailowsky S, Menini C, Naquet R. Relationship between tolerance to $\mathrm{GABA}_{\mathrm{A}}$ agonist and bursting properties in neocortical neurones during GABA-withdrawal syndrome, Brain Res 1989; 498: 289-298.

Silva-Barrat C, Araneda S, Menini C, Champagnat $\mathrm{J}$, Naquet R. Burst generation in neocortical neurons after GABA-withdrawal in the rat, $\mathrm{J}$ Neurophysiol 1992; 67: 715-727.

Silva-Barrat C, Champagnat J, Leiva J, Pavlik V. Noradrenaline mediates paradoxical effects on rat neocortical neurons after GABA-withdrawal, J Neurophysiol 1994; 71: 1139-1150.

Silva-Barrat C, Champagnat J. A Potassium current controls burst termination in rat neocortical neurons after GABA-withdrawal. Neurosci Lett 1995; 189: 105-108. 

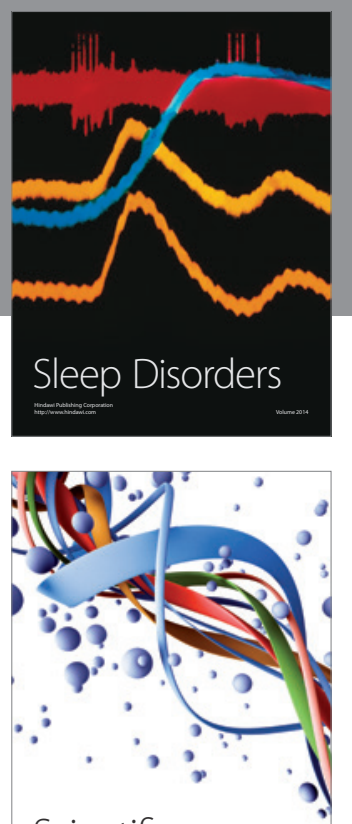

Scientifica
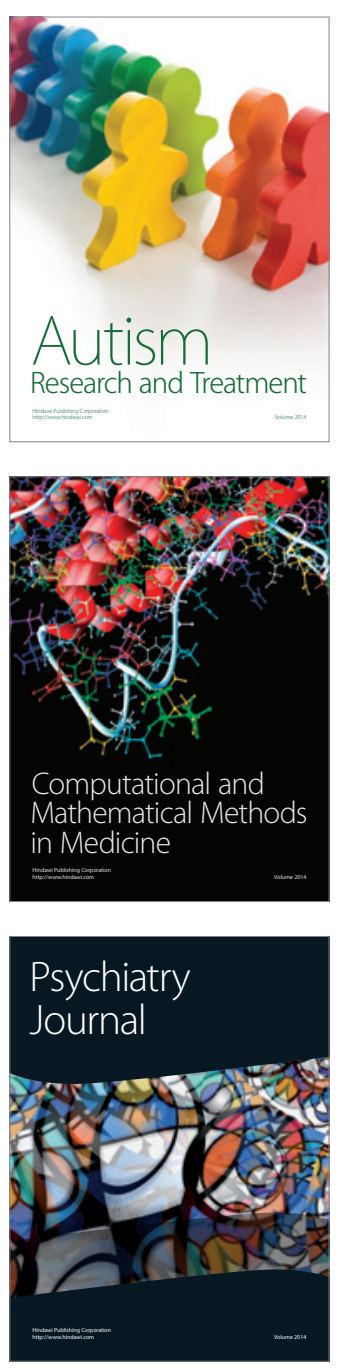
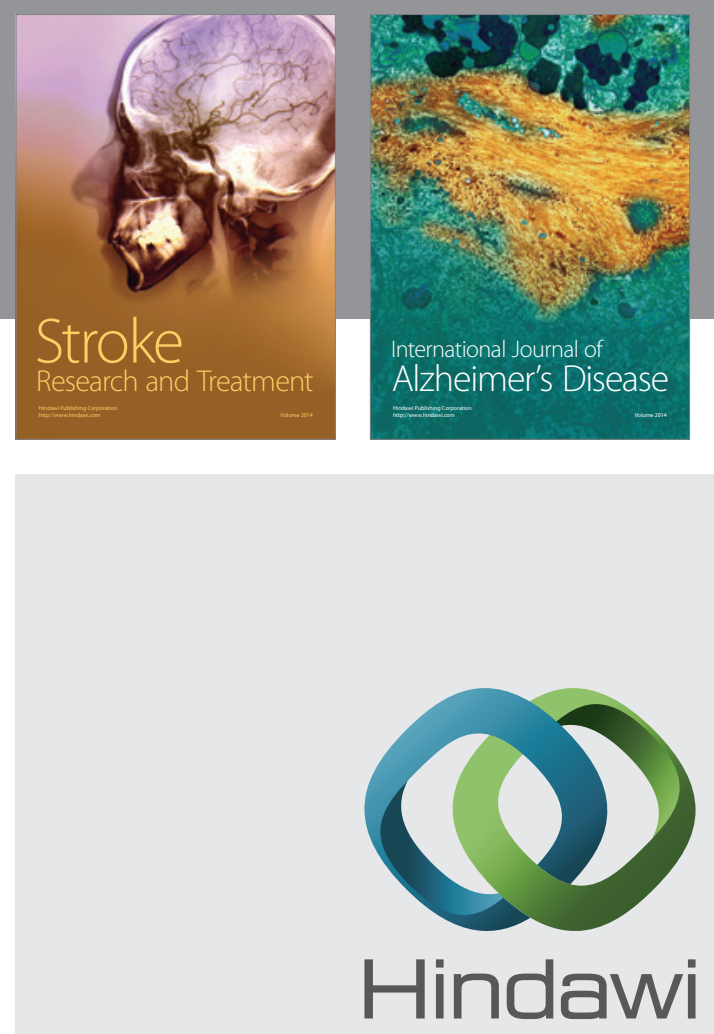

Submit your manuscripts at

http://www.hindawi.com
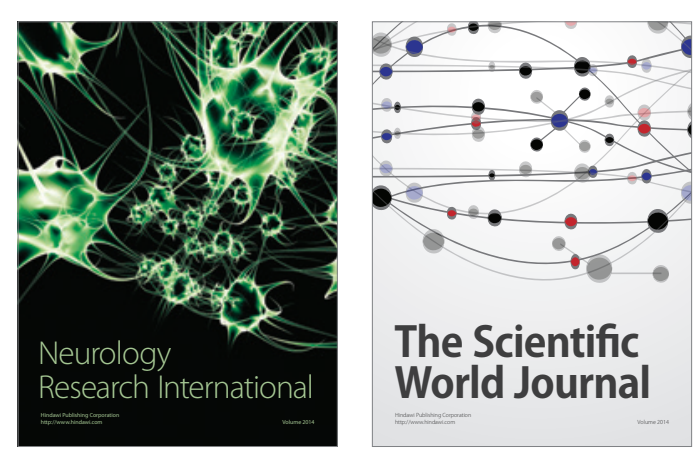

The Scientific World Journal

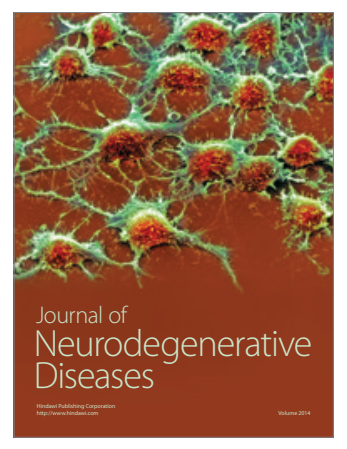

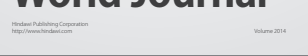

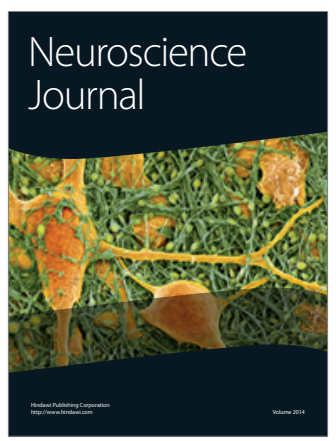

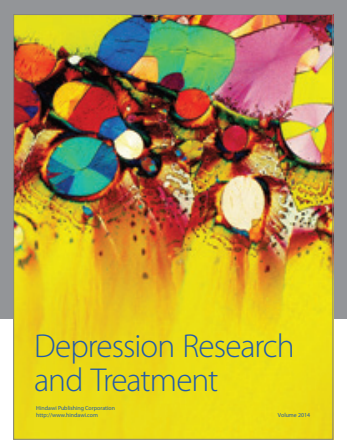
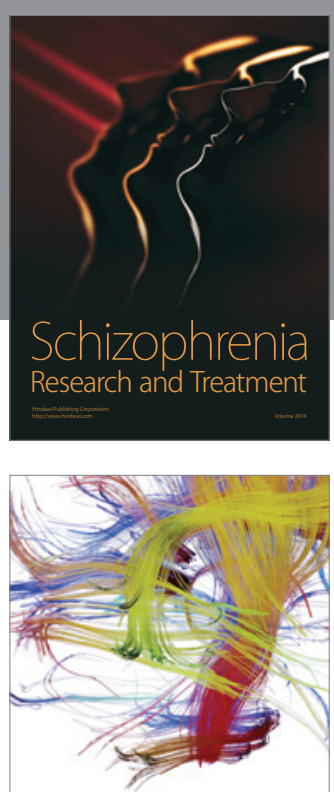

Brain Science

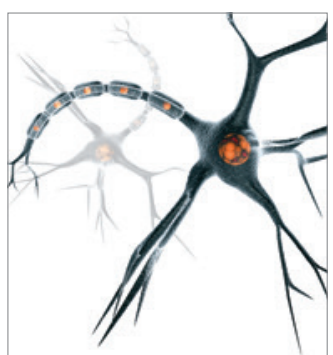

Neural Plasticity
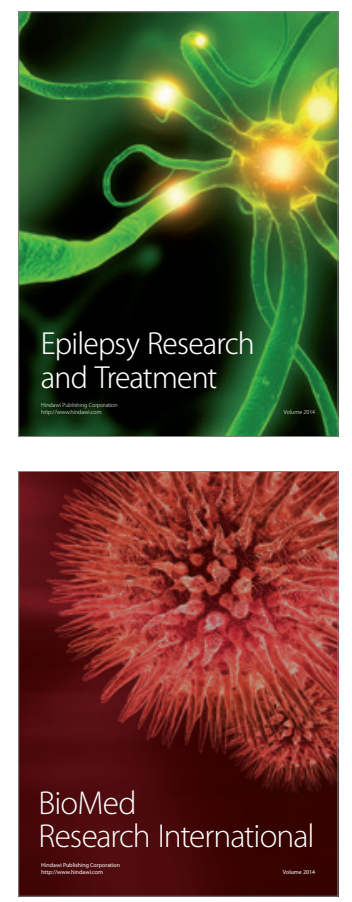

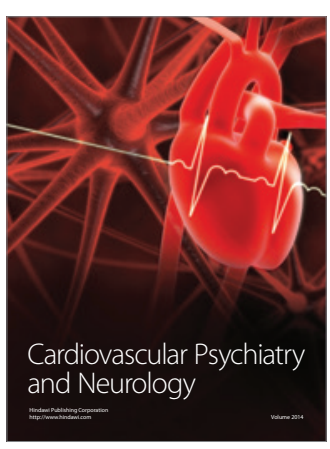

Parkinson's

Disease
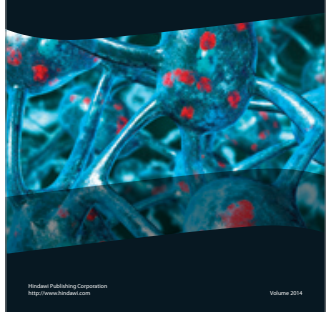